\title{
Simulation of diabetic eye disease to compare screening policies
}

\author{
Ruth Davies, Paul Sullivan, Chris Canning
}

\begin{abstract}
Aims/background-The purpose of the project was to develop a technique for evaluating screening policies in the treatment of insulin dependent diabetic retinopathy. The study was concerned with patients who contracted the disease, aged under 35 years. Simulation was used to describe the progress of a cohort of patients through disease and treatment.

Method-Data, derived from a literature survey of European and American population and clinic studies, were used to model as closely as possible the development of retinopathy in all its stages, together with the effects of screening and treatment. The model output was validated against published data.

Results-The results showed that where screening sensitivities are high, the frequency of screening makes little difference to the years of sight saved, but it does make a difference if screening sensitivities are close to $50 \%$.

Conclusions-Although annual screening is normally desirable, biannual screening could be considered where patient compliance and screening sensitivities are both high.
\end{abstract}

(Br f Ophthalmol 1996;80:945-950)

Timely retinal laser photocoagulation is effective in preventing or delaying the onset of blindness in many patients ${ }^{1}$ with diabetic retinopathy. Bingley and $\mathrm{Gale}^{2}$ found that, based on a study in the Oxford region, there are about 15.6 cases of diabetes per 100000 population per year diagnosed among the under 21 year olds. The majority of patients with insulin dependent diabetes may be expected to develop some form of diabetic retinopathy. ${ }^{3}$ There is, however, a period during which the retinopathy is asymptomatic but can be detected and treated to preserve sight. Primary screening programmes have been established with general practitioners or optometrists using various different screening techniques. Screening can also be done by ophthalmologists or diabetes physicians.

This paper is concerned only with background and proliferative retinopathy and with macular oedema although, clearly, cataracts and other eye conditions may also be picked up in the screening process. Screening for macular oedema relies more heavily on the measurement of best corrected visual acuities than techniques such as direct ophthalmoscopy. In this study we assumed that screening for both types of condition could be done at the same time and had the same sensitivity and specificity.

Studies indicate that trained ophthalmic surgeons may be the most accurate screeners, ${ }^{5}$ but they are a limited and expensive resource. Screening done by other professional groups may have less predictive accuracy, but is more widely available and may be cheaper. The better screening techniques and shorter screening intervals are more effective in saving sight but are more expensive and require more health resources. The diabetic patients with insulin dependent diabetes have a lower age profile and a different vulnerability to the different eye conditions from patients with non-insulin dependent diabetes. Although there are fewer patients with insulin dependent diabetes in the population, this group is likely to gain more long term benefit from screening because of their age. This study describes a simulation of insulin dependent diabetic patients which has been developed to explore the trade off between the use of different personnel, the various screening techniques, and the screening intervals.

\section{Method}

THE SIMULATION

A simulation approach, designed for describing patient systems ${ }^{6-9}$ was applied to the present study. A model was developed which represents a cohort of insulin dependent diabetic patients progressing from an initial diagnosis of diabetes, through different stages of eye disease, until death (see Fig 1). It uses published data sources to model as closely as possible how the UK population of diabetes patients develops retinopathy and responds to treatment. As the time spent in each disease state is variable, some patients progress through several stages of disease, while others die without developing any retinopathy at all.

While alive, a patient is assumed to progress first from no retinopathy to background retinopathy (states 2 to 5 in the Wisconsin study ${ }^{3}$ ) and then either to proliferative retinopathy (state 6 or greater in the Wisconsin Study $^{3}$ ) or to macular oedema. Patients may subsequently develop both. Patients with macular oedema may develop clinically significant macular oedema (as defined in the ETDRS study'). Patients with clinically significant macular oedema may progress to central vision loss whereas those with proliferative retinopathy may develop severe vision loss (defined as less than $6 / 60$ vision). Once proliferative retinopathy or clinically significant macular oedema 


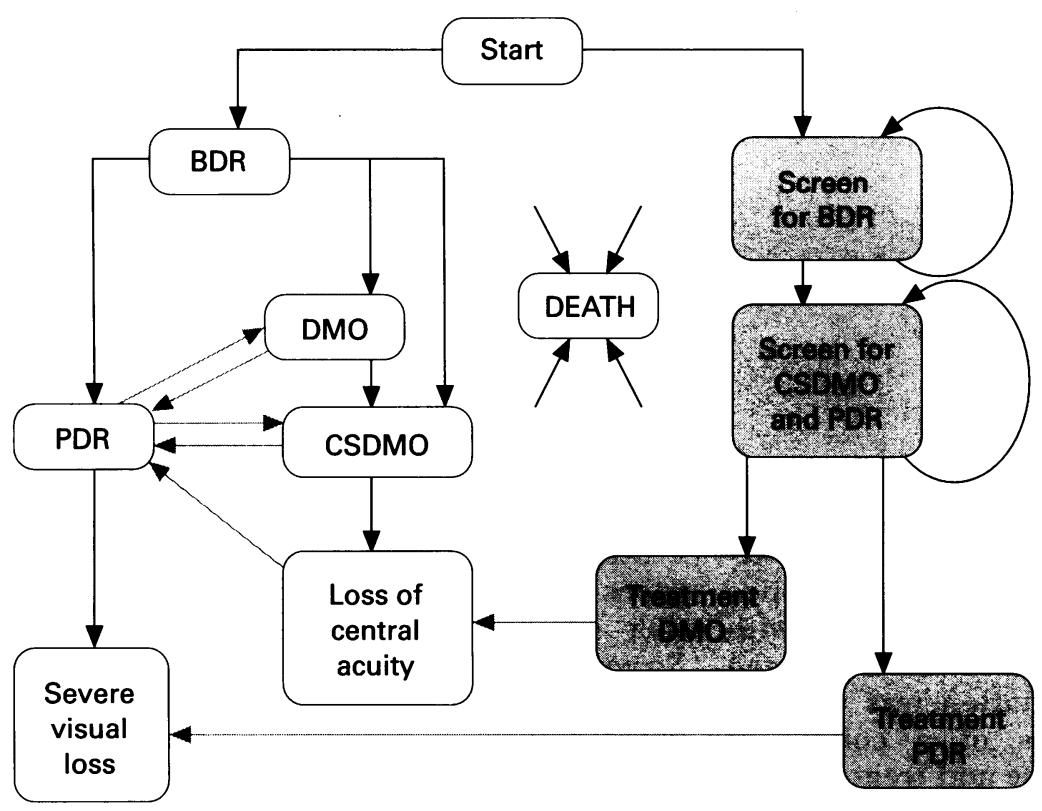

Figure 1 The flow of patients in the simulation from event to event. The shaded blocks show the screening and treatment events. The shaded arrows indicate movement between states to acquire macular oedema as well as proliferative retinopathy, or vice versa. Death may take place from any event. $B D R=$ background retinopathy; $P D R=$ proliferative diabetic retinopathy; $D M O=$ diabetic macular oedema; $C S D M O=$ clinically significant DMO. event is derived from the probability of that event occurring in each time interval (see Davies $\left.^{9}\right)$. The times in the simulation are sampled from the probability distributions, using random numbers. In order to increase the accuracy of the estimates, each simulation run was repeated with several different sets of random numbers and the results were averaged. The simulation constructs records of events of simulated patients and summary information.

There are some further assumptions incorporated in the model:

(1) the likelihood of a false positive or negative result from any given screening episode is independent of that patient's previous history;

(2) the probability of dying is related to age and the degree of retinopathy and, where proliferative diabetic retinopathy and macular oedema coexist, their effect on mortality is cumulative;

(3) 'patients' are not lost to follow up but stay in the simulation until they die;

(4) an initial assumption was made that screening took place at the exact interval specified; the effects of relaxing this assumption were tested.

The output was validated against published epidemiological data. Once the model appeared to be in reasonable agreement with the published papers, it was used to assess the relative workload and benefits arising from the different screening options. conditions will need both types of treatment.

Patients' experiences over a period of time are divided into events, shown by the boxes in Figure 1. The simulation program moves forward through simulated time, not in regular time intervals, but from one event to the next, in time order, regardless of which patient is involved. Details of all future events with their times and patient identifications are kept in a list of scheduled events for all patients (called a future events list). Events are removed from the future events list as they are actioned. Individual patients' life histories are created from information generated by these events. When the simulation program actions a particular event for a patient, it needs to know all the possible next events for that patient. There may be some already scheduled in the future events list; these may be removed or reset and new events scheduled.

The facility to schedule more than one event at once for an individual patient is a characteristic of Davies's simulation approach and has been used in other medical models. ${ }^{6-8}$ The advantage of using it in a screening model is that screening takes place independently of disease progression. When screening takes place, it may (1) detect disease where it does not exist (false positives), in which case the patient is referred back for further screening; (2) detect disease correctly; or (3) miss disease which is present (false negative) and screening continues. Once treatable disease is detected, then 'treatment' in the simulation, is simply a resampling of the time to severe visual loss, or central visual loss.

The different ways of progressing through the events are shown in Figure 1. The probability distribution of the time to a next

\section{SCREENING OPTIONS}

The screening options discussed in this paper are selected examples from a wide range of possibilities. Screening was assumed to be done by ophthalmologists, diabetes physicians, or general practitioners. Junior hospital doctors were not identified separately but may be assumed to fall within the range of sensitivities examined in the simulation. Optometrists were found by Buxton et $a l^{10}$ to have similar sensitivities and specificities to general practitioners. In this study, we used Buxton's results from ophthalmoscopy, rather than from nonmydriatic photography.

Different assumptions are made about the process of screening:

(1) Screening until the first detection of disease is done by the relevant screenersophthalmologists, diabetes physicians, or general practitioners. After that, and until treatment, screening is done by ophthalmologists. The screening modes are denoted $\mathrm{Oph}, \mathrm{Ph} 1$ and GP1, respectively.

(2) All screening until treatment is done by diabetes or general physicians or optometrists, except for isolated visits to ophthalmologists arising from false positive detections of disease. The screening modes are denoted $\mathrm{Ph} 2$ and GP2, respectively.

(3) This option shows what happens when patients are non-compliant and do not attend for screening promptly at the specified screening intervals. The effects of non-compliance are demonstrated by modifying GP2 to incorporate delays in attendance from 0 to 6 months in length (GP3). 
Two sets of screening frequencies are reported:

Less frequent screening-once every 2 years until any retinopathy is detected, and annually afterwards.

More frequent screening - annually before any retinopathy is detected, and twice yearly afterwards.

Each of the screening processes was combined with each of the two sets of screening frequencies to provide 12 sets of results in all.

\section{DATA USED IN THE SIMULATION}

Age of onset

Data on patients between ages 0 and 35 years were obtained from Gamble ${ }^{11}$ who collected data on 1460 cases from Liverpool and from throughout Denmark. Although more recent studies are available, ${ }^{12}$ this paper was chosen because it enabled us to derive the proportion of a cohort of new patients in each age band.

\section{Transfer between states}

The probability of retinopathy developing and progressing before puberty is small but increases in adults. ${ }^{3}$ The probability of adults over the age of 20 progressing from one state to another is assumed to be the same from year to year. Pretreatment data about the progression of patients to visual loss are based on studies of selected populations, in which one eye was treated and one was not. ${ }^{13-15}$ The simulation results were then validated against Wisconsin prevalence data ${ }^{16}$ and the probabilities rechecked and recalculated to eliminate any inconsistencies. The validation is discussed below. The probabilities used are shown in Table 1(A).

\section{Accuracy of screening}

Buxton et $a l^{10}$ studied the sensitivity and specificity of a number of screening options in comparison with ophthalmic clinical assistants who were assigned a sensitivity and specificity of 1.0. Table1(C) shows the values used in this study. The values for the general practitioners and optometrists, which were very similar, have been grouped together.

\section{Effect of treatment}

Timely laser treatment of patients with severe non-proliferative retinopathy or early proliferative retinopathy could reduce the risk of severe visual loss by as much as $90 \%$ over untreated patients. ${ }^{13}$ In practice, a screening programme will not always pick up the retinopathy at such an early stage; a more conservative $66 \%$ improvement in outcome was therefore chosen for use in this study. The effects of treating clinically significant macular oedema are more difficult to identify. We chose a figure of $50 \%$, based on an early study. ${ }^{15} \mathrm{~A}$ recent paper from the Early Treatment of Diabetic Retinopathy Research Group ${ }^{17}$ explored the effects of immediate rather than deferred treatment for clinically significant macular oedema. They found that the effects of deferral differed depending on the type and location of the oedema. It was not possible to make a direct comparison with previous papers because, of those deferred, more than $60 \%$ had treatment within 5 years. However, the chosen figure of $50 \%$ still appeared to be a reasonable estimate.

\section{Mortality}

It is clear from the Wisconsin study of diabetes patients ${ }^{18}$ that, when age and other factors have been taken into account, the mortality rate increases as retinopathy worsens. That is not to say that retinopathy causes increased morbidity and mortality but may be symptomatic of it. In the simulation, instead of assuming a continuous decline in survival with the progression of eye disease, we used Javitt and colleagues' model of mortality ${ }^{19}$ which assumed that survival is related to age and to the simulation states: no eye disease, background retinopathy, proliferative retinopathy, and macular oedema. The probability of dying in any particular year was $a+b r$. The constants $a$ and $b$ depended on the simulation state and $r$ was the age specific mortality from published life tables. ${ }^{21}$

In order to check the validity of the survival data, the simulation was run several times to provide the overall population survival of the simulated diabetic population. This was compared with population studies of diabetes patients. ${ }^{22-24}$ Two problems were identified with Javitt's model figures.

Table 1 Details of factors used in simulation

(A) The annual probabilities of changing state

\begin{tabular}{llll}
\hline From & To & Age & $\begin{array}{l}\text { Annual } \\
\text { probability }\end{array}$ \\
\hline None & BDR & $12-17$ years & 0.150 \\
None & BDR & over 17 years & 0.220 \\
BDR & PDR & $15-20$ years & 0.008 \\
BDR & PDR & over 20 years & 0.048 \\
& Severe visual & & 0.075 \\
PDR & loss & - & $17-20$ years \\
BDR & DMO & 0.005 \\
BDR & DMO & over 20 years & 0.010 \\
BDR & CSDMO & - & 0.010 \\
DMO & CSDMO & - & 0.010 \\
CSDMO & Loss of central & & 0.080 \\
\hline
\end{tabular}

(B) Constants used in the simulation where $a+b r$ is the probability death in any year and $r$ is the probability for the normal population of the same age and sex

\begin{tabular}{lll}
\hline Eye problem & $a$ & $b$ \\
\hline None & 0.000 & 1.0 \\
BDR & 0.000 & 2.0 \\
DMO & 0.003 & 3.75 \\
PDR (1) & 0.003 & 3.75 \\
PDR (2) & 0.006 & 7.5 \\
PDR (3) & 0.012 & 15.0 \\
\hline
\end{tabular}

(C) Accuracy

\begin{tabular}{llll}
\hline Agent & Screening method & Sensitivity & Specificity \\
\hline $\begin{array}{l}\text { Diabetic } \\
\text { physician }\end{array}$ & Ophthalmoscopy & $67 \%$ & $96 \%$ \\
$\begin{array}{l}\text { GP or } \\
\text { optometrist }\end{array}$ & Ophthalmoscopy & $52 \%$ & $91 \%$ \\
\hline
\end{tabular}

BDR = background retinopathy; $P D R=$ proliferative diabetic retinopathy; DMO = diabetic macular oedema; CSDMO = clinically significant DMO.

PDR (1) = the start of PDR; PDR (2) = halfway to PDR (3); PDR (3) = the time of predicted severe visual loss, if untreated. Screening sensitivity and specificity based on work by Buxton
et al. 


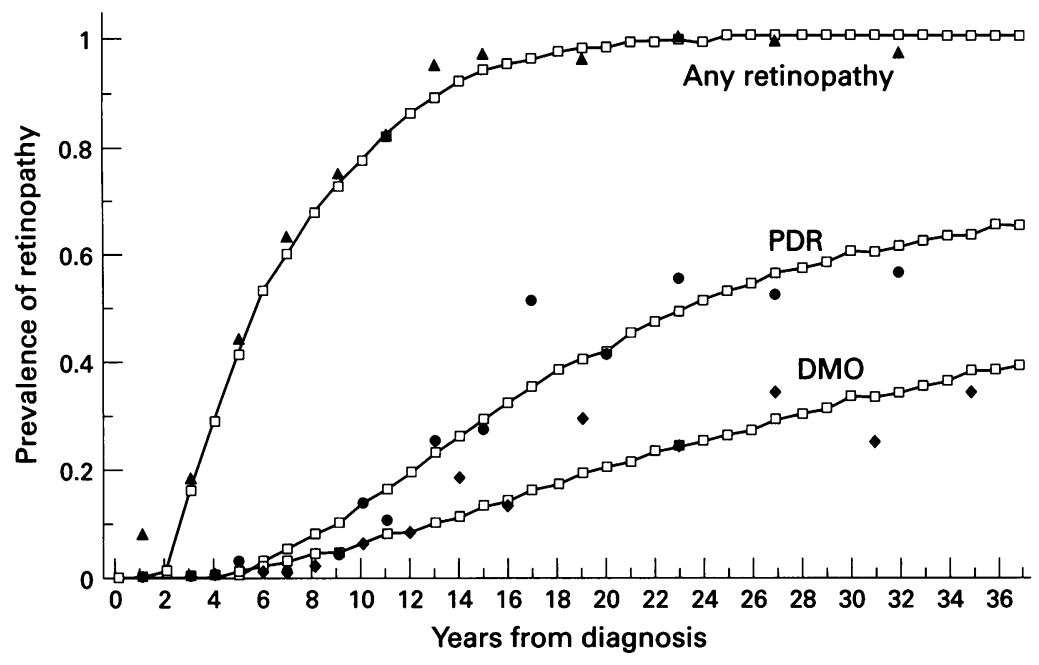

- Simulation $\quad$ - WESDR proliferative retinopathy

Figure 2 Comparison between estimated prevalence of background and proliferative diabetic retinopathy and of macular oedema derived from the simulation and from the Wisconsin studies. ${ }^{16} 25$

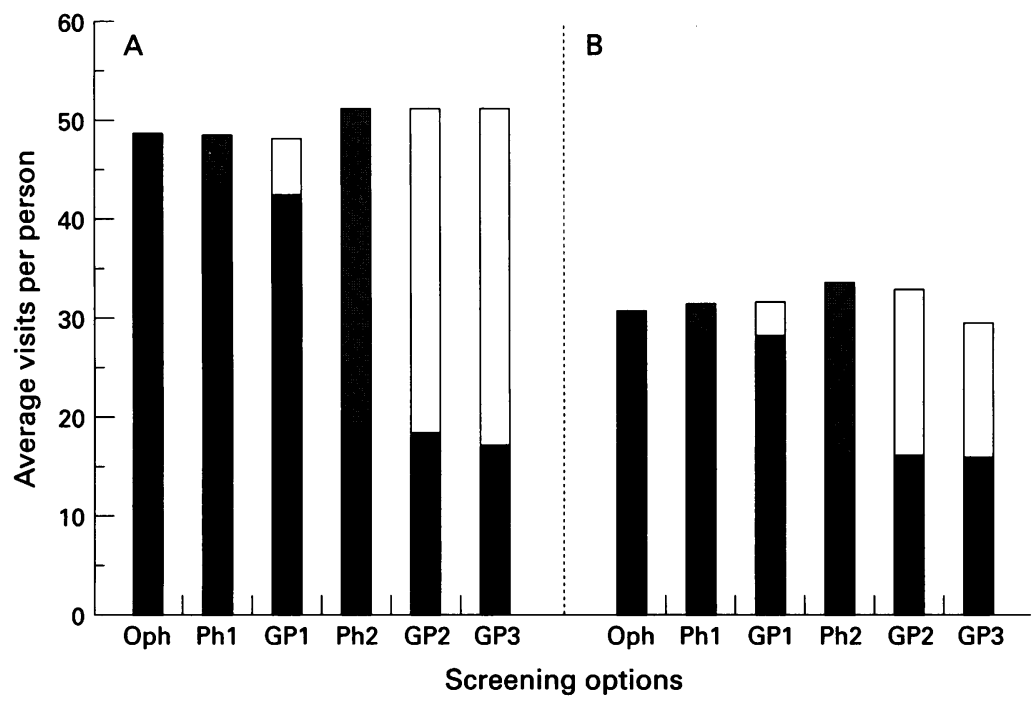

Eye clinic Physician $\square$ GP

Figure 3 Visits generated by screening policies. (See definitions in text.) (A) Frequent screening; (B) less frequent screening.

(1) In the early years (up to 20) the population survival of the simulated population was much worse than that demonstrated in the population studies (see Table 2).

(2) The Wisconsin study $^{18}$ showed that mortality continues to decline as the proliferative retinopathy becomes more extensive and sight threatening.

To address the second problem two further events were defined-the time when the patient would have severe visual loss if untreated and a time halfway between the onset of proliferative retinopathy and that time. The survival figures were assumed to change at these points in time. Various figures were tested in the survival formula to obtain a better fit to the published data; the constants chosen are shown in Table $1(\mathrm{~B})$.

\section{Results}

VALIDATION

The simulation was first validated against published papers on the prevalence of retinopathy in a population. ${ }^{16}$ The average number of years patients spend in a particular state (for example, with proliferative retinopathy), divided by the total average years of life following the diagnosis of diabetes, was taken to be equivalent to the prevalence of that state in the diabetic population.

Figure 2 shows that the Wisconsin prevalence of background retinopathy and proliferative retinopathy by year of diagnosis fits the simulation output well. Less information was available for macular oedema ${ }^{25}$ but the fit was also good.

Table 2 shows that the overall mortality of the simulated diabetic population, in the early years after diagnosis, was of the same order of magnitude as that found in various recent studies. $22-24$

\section{Effect of screening options}

Figure 3 shows that where screening after the first detection of disease is done by diabetes physicians or general practitioners ( $\mathrm{Phl}$ compared with Ph2 and GP1 compared with GP2), eye departments are relieved of a considerable burden of routine work. Clearly, the workload is much lower when screening is half as frequent.

Figure 4 shows the average years of sight saved from loss of central acuity arising from macular oedema and severe visual loss from proliferative retinopathy, under the different screening policies. The less frequent screening by ophthalmologists (Oph) appears to be as good as more frequent screening by a general practitioner or optometrist (GP2).

Figure 4 shows that the average years of central vision loss, arising from macular oedema alone, seem to be insensitive to the screening policy. This may be because much of the treatable macular oedema in insulin dependent diabetes develops after patients have proliferative retinopathy and after they have been treated for it. The macular oedema is thus

Table 2 Predicted survival of the diabetic population, using the simulation, compared with published population studies

\begin{tabular}{|c|c|c|c|c|c|c|c|}
\hline Source & Simulation & & Dorman et & $t a l^{22}$ & & Modan et al ${ }^{23}$ & foner et al ${ }^{24}$ \\
\hline $\begin{array}{l}\text { Age range } \\
\text { Source } \\
\text { Years }\end{array}$ & $\begin{array}{l}\text { Less than } 18 \text { years } \\
\text { Data from Table } 1\end{array}$ & $\begin{array}{l}\text { Less than } 18 \text { years } \\
\text { Javitt's data }{ }^{19}\end{array}$ & $\begin{array}{l}\text { Less than } \\
1950-7\end{array}$ & $\begin{array}{l}18 \text { years } \\
1958-65\end{array}$ & $1966-71$ & $\begin{array}{l}\text { Less than } 18 \text { years } \\
1973-88\end{array}$ & $\begin{array}{l}\text { Less than } 15 \text { years } \\
\text { 1973-88 }\end{array}$ \\
\hline 5 & 0.05 & 1.10 & 3.1 & 1.9 & 0.7 & - & - \\
\hline 10 & 0.75 & 3.80 & 4.1 & 3.6 & 1.4 & 0.33 & 0.46 \\
\hline 15 & 2.25 & 8.20 & 6.2 & 5.3 & - & - & 1.00 \\
\hline 20 & 4.50 & 13.65 & 14.5 & 12.9 & - & 5.23 & - \\
\hline
\end{tabular}




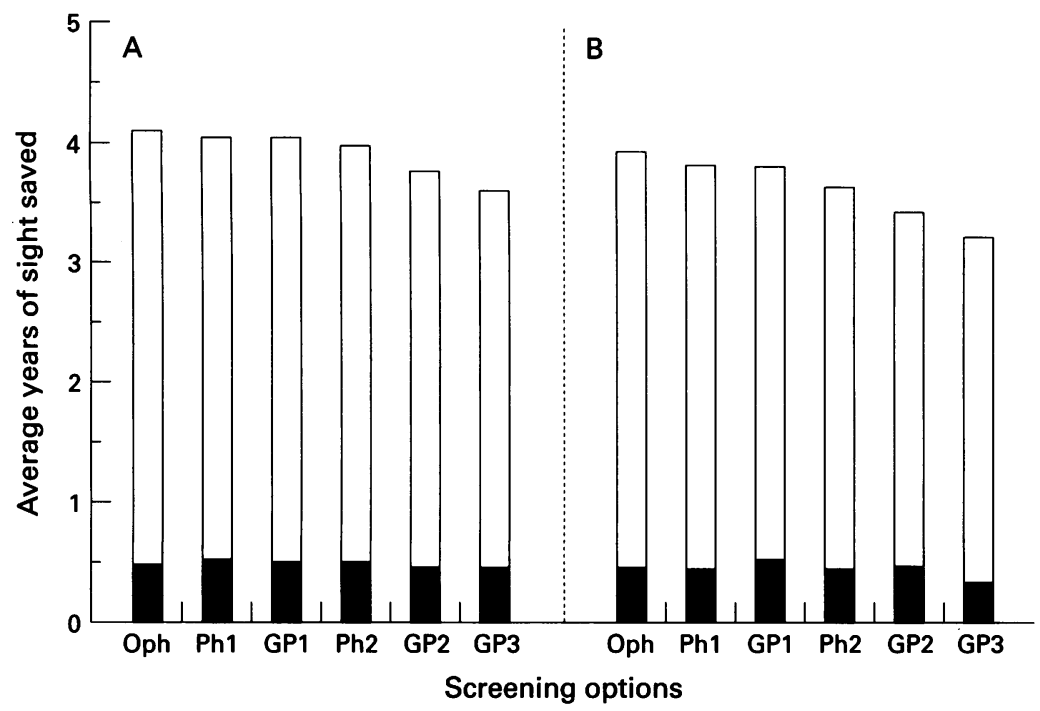

Reading loss $\square$ Severe vision loss

Figure 4 Years of sight saved by the different screening policies. With no treatment average years of severe visual loss $=8.8$ years and average years of loss of central acuity $=2.0$ years. (See definitions in text.) (A) Frequent screening; (B) less frequent screening.

assumed to be picked up at the repeat outpatient visits which have the same frequency under all the screening options.

For the third option, GP3, Figures 3 and 4 show the overall number of screening sessions is reduced and the overall screening policy is correspondingly less effective. Thus delays by the medical services or a lack of compliance by patients can be seen to have a significant impact on the effectiveness of a screening policy.

Figure 5 shows the incidence of sight loss by age (that is, the average number out of a cohort of 1000 patients), either due to the loss of central acuity or to severe visual loss from proliferative retinopathy. It can be seen that treatment decreases sight loss in all age groups.

\section{Discussion}

Our current work shows that for accurate screeners, the screening interval (within the range tested) makes very little difference to the resulting years of sight saved. The prevalence

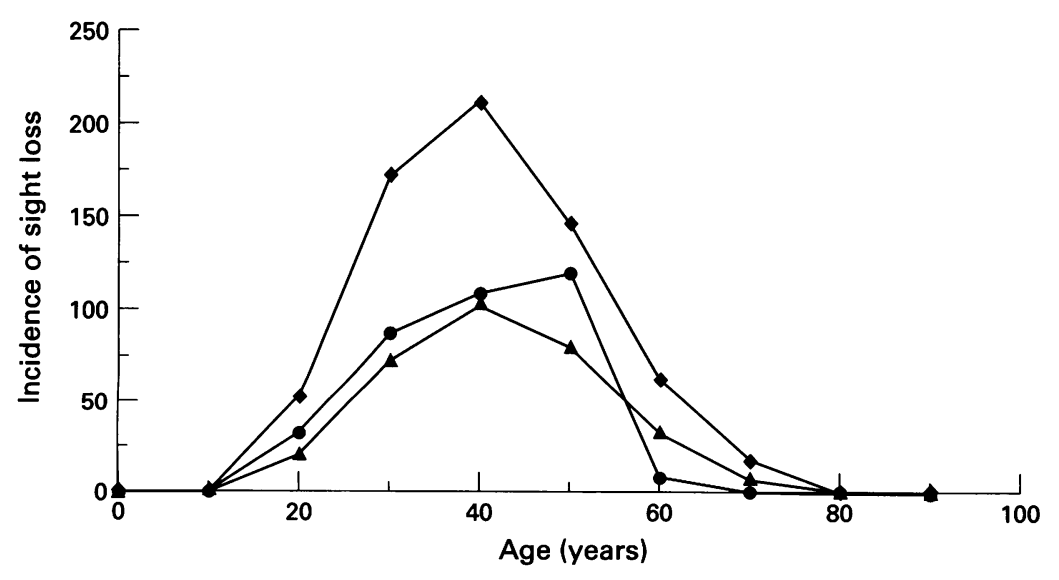

$\bullet$ No screening $\bullet$ GP2 $\triangle$ Ophth

Figure 5 Average number of patients in each age group developing severe or central vision loss in each age group. GP2 is shown for less frequent screening. of loss of central acuity can be reduced by approximately $30 \%$ and of severe visual loss by $46 \%$, compared with a population of unscreened patients. The apparent cost savings of less frequent screening by more accurate screeners (ophthalmologists and diabetes physicians) may be difficult to realise because of resource constraints in the hospital sector. Davies ${ }^{9}$ has used American costs to examine the trade off between screening intervals, accuracy, and cost. Reliable UK data on costs and on the prevalence of diabetic eye disease are needed in order provide more useful information for those planning and funding services.

The simulation is dependent on historical data and there are trends which need further exploration. Recent European data ${ }^{26}$ indicated that the prevalence of retinopathy by age in the diabetic population is lower than that demonstrated in the Wisconsin studies ${ }^{16}$ and may indicate that its prevalence is falling. These effects may be offset by a gradual decline in the expected mortality of diabetes patients. ${ }^{22}$

Javitt et al ${ }^{1920}$ used a simulation approach for the same purpose but theirs is less flexible. In our study, the age of onset of diabetes is sampled (rather than remaining fixed), macular oedema and clinically significant macular oedema are separated, and a change of retinopathy state (for example, from background to proliferative retinopathy) can occur independently of screening. We have developed a tool which has considerable potential value in planning and policy making in the management of diabetes. The simulation can be extended to evaluate the further options for screening for eye disease, such as the use of fundus photography, either non-mydriatic or after pupil dilatation, and can be used to look at different treatment policies and poor patient compliance. The Diabetes Control and Complications Trial Research Group ${ }^{27}$ has shown that the introduction of an intensive therapy regimen to achieve blood glucose levels close to the normal range in insulin dependent diabetic patients slows the development of retinopathy. The simulation could explore the screening requirements of patients on intensive therapy compared with those on conventional treatment. It could also be used to examine the benefits of screening the much larger population of patients with non-insulin dependent diabetes.

1 Early Treatment Diabetic Retinopathy Study Research Group. Early photocoagulation for diabetic retinopathy: ETDRS report number 9. Ophthalmology 1991;98:766-85.

2 Bingley PJ, Gale EAM. Incidence of insulin dependent diabetes in England: a study in the Oxford region. 1985-6. diabetes in England: a st

3 Klein R, Klein BEK, Moss SE, Davis MD, DeMets DL. The Wisconsin Epidemiologic Study of Diabetic Retinopathy. IX Four-year incidence and progression of diabetic retinopathy when age at diagnosis is less than 30 years. Arch Ophthalmol 1989;107:237-43.

4 Alexander MM, Canning CR. A telephone study of diabetic retinopathy and the diabetic miniclinic in general practice: a regional study in Wessex. Pract Diabetes Int 1995;12:28-30.

5 Sussman EJ, Tsiaras WG, Soper KA. Diagnosis of diabetic eye disease. $\mathcal{F A M A}$ 1982;247:3231-4.

6 Davies R, Davies HTO. Modelling patient flows and resource provision in health systems. Omega International fournal of Management Science 1994;22:123-31.

7 Bolger PG, Davies R. Simulation model for planning renal services in a district health authority. $B M \mathcal{F} 1992 ; 305: 605-8$. 
8 Davies R. Simulation for planning services for patients with coronary artery disease. Eur $\mathcal{f}$ Operational Res 1994;71: 323-32.

9 Davies R. A simulation to evaluate screening policies for the treatment of diabetic retinopathy. In: Anderson JG, Katzper M, eds. Health sciences, physiological and pharmacological simulation studies. San Diego: Society for Computer Simulation, 1995;25-30.

10 Buxton MJ, Sculpher MJ, Ferguson BA, Humphreys JE, Altman JFB, Spiegelhalter DJ, et al. Screening for treatable diabetic retinopathy: a comparison of different methods. Diabet Med 1990;8:371-7.

11 Gamble DR. The epidemiology of insulin dependent diabetes, with particular reference to the relationship of virus infection to its etiology. Epidemiol Rev 1980;2:49-70.

12 Green A, Gale E. The aetiology and pathogenesis of IDPM A, Gale E. The aetiology and pathogenesis of Paoz L, Fuller J, eds. Diabetes in Europe. London: John Paoz L, Fuller J, eds.

13 British Multicentre Study Group. Photocoagulation for proliferative diabetic retinopathy: a randomised controlled clinical trial using the xenon-arc. Diabetologia 1984;26:109-15.

14 The Diabetic Retinopathy Study Research Group. Photocoagulation treatment of proliferative diabetic retinopathy: the second report of diabetic retinopathy study findings. Ophthalmology 1978;85:82-106.

15 Anonymous. Photocoagulation in treatment of diabetic maculopathy. Interim report of a multicentre controlled study. Lancet 1975;2:1110-3.

16 Klein R, Klein BEK, Moss SE, Davis MD, DeMets DL. The Wisconsin Epidemiologic Study of Diabetic Retinopathy. II Prevalence and risk of diabetes mellitus when age at diagnosis Prevalence and risk of diabetes mellitus when age at diag
is less than 30 years. Arch Ophthalmol 1984;102:520-6.

17 Early Treatment of Diabetic Retinopathy Research Group. Focal photocoagulation treatment of diabetic macular edema. Relationship of treatment effect to fluorescein angiographic and other retinal characteristics at baseline: ETDRS Report No 19. Arch Ophthalmol 1995;113:1144-55.
18 Klein R, Moss SE, Klein BEK, DeMets DL. Relation of ocular and systemic factors to survival in diabetes. Arch Intern Med 1989;149:266-72.

19 Javitt JC, Aiello LP, Bassi LJ, Chiang YP, Canner JK. Detecting and treating retinopathy in patients with type 1 diabetes mellitus. Savings associated with improved implementation of current guidelines. Ophthalmology 1991;98: 1565-74.

20 Fendrick AM, Javitt JC, Chiang YP. Cost-effectiveness of the screening and treatment of diabetic retinopathy. What are the costs of underutilization? International fournal of Technology Assessment in Health Care 1992;8:694-707.

21 Office of Population Censuses and Surveys Series DH1 No 24 Mortality statistics-general. London: HMSO, 1992.

22 Dorman JS, Laporte RE, Kuller LH, Cruikshanks KJ, Orchard TJ, Wagener DK, et al. The Pittsburgh insulindependent diabetes mellitus (IDDM) morbidity and dependent diabetes mellitus (IDDM) morbidity and

23 Modan M, Karp M, Bauman B, Gordon O, Danon YL, Laron Z. Mortality in Israeli Jewish patients with type 1 (insulin-dependent) diabetes mellitus diagnosed prior to 18 years of age: a population based study. Diabetologia 1991;34:515-20.

24 Joner G, Patrick S. The mortality of children with type 1 (insulin-dependent) diabetes mellitus in Norway, 19731988. Diabetologia 1991;34:29-32.

25 Klein R, Klein BEK, Moss SE, Davis MD, DeMets DL. The Wisconsin Epidemiologic Study of Diabetic Retinopathy. IV Diabetic macular edema. Ophthalmology 1984;91:1464-74.

26 Aldington SJ, Kohner EM, Meuer S, Sjolie A-K. Methodology for retinal photography and assessment of diabetic retinopathy: the EUROTAB IDDM complications study. Diabetologia 1995;38:437-44.

27 The Diabetes Control and Complications Trial Research Group. The effect of intensive treatment of diabetes on the development and progression of long-term complications in insulin dependent diabetes mellitus. N Engl F Med 1993; 329:977-86. 